\title{
Prospects for the Formation of a Global Natural Gas Market: Price Analysis of European, Asian, American Gas Markets
}

\author{
Andrey V. Novikov ${ }^{1, *}$, Vladimir Sh. Urazgaliev ${ }^{1}$, and Mikhail V. Titkov ${ }^{1}$ \\ ${ }^{1}$ St. Petersburg State University, Faculty of Economics, Universitetskaya nab., 7-9, St. Petersburg \\ 199034, Russia
}

\begin{abstract}
.
Research background: Natural gas markets are facing an ongoing process of diffusion of natural gas liquefaction (LNG) technology. High mobility and relative ease of $\mathrm{LNG}$ use predetermine a huge potential for globalization of gas markets and the formation of a single price space similar to the oil world market.

Purpose of the article: The purpose of the article is determining the degree of gas markets convergence and offering an assessment of the prospects for gas globalization.

Methods: The authors conducted a comparative analysis of statistics on historical prices in the gas markets, reviewed the scientific and practiceoriented literature on this topic. The authors developed a brief forecast model based on statistical methods to develop their own assessment of the prospects for the development of a single global gas market.

Findings \& Value added: The paper contains the most relevant comparative assessments of the three key gas markets (Europe, Asia, USA) and descripts an authors' assessment of the potential for the emergence of a global gas market. On the one hand, the authors revealed a fairly high correlation between LNG prices worldwide, on the other hand, LNG supplies are not the only form of gas supplies. In addition, regional pricing features lead to the relative independence of the three markets among themselves. Moreover, the current global crisis may slow down the development of global gas market due to restrictions on the profitability of potentially new LNG projects.
\end{abstract}

Keywords: natural gas; LNG market; gas price analysis; global gas market.

JEL Classification: L11; Q31; Q37.

\footnotetext{
*Corresponding author: a.v.novikov@spbu.ru
} 


\section{Introduction}

Natural gas is one of the most important components of energy consumption worldwide, along with oil and coal. Its consumption is closely connected not only with heating and power generation, but also with the production of various gas chemical products. Moreover, natural gas is often claimed to be a more modern, environmentally friendly and efficient resource than coal and even oil.

Natural gas trade is often compared with oil trade, as evidenced by a number of researchers who have found long-term cointegration between oil and natural gas prices [1]. Why is this happening? Oil and natural gas are, first, the energy resources required by all countries in the world; secondly, both resources are actively becoming the subject of trading on exchanges, specific financial instruments are developed. However, there are prerequisites to believe that both of these resources are not equal in their globality.

These prerequisites are that: 1) world trade requires cheap and mobile delivery of goods anywhere in the world. LNG technologies are currently being developed, but a significant portion of natural gas is transported by pipeline. Moreover, additional economic costs of LNG shipping may be too high and lead to the market inefficiency [2]. 2) In modern conditions of development of the world's economy, a single world market for any product implies the universal prevalence of hub trading and the development of financial instruments. However, it is known that natural gas is often traded under long-term contracts or under oil indexation scheme.

The aim of the article is to answer the question: "What is the current level of integration of natural gas markets and what are the prospects for this process?"

\section{Hypotheses and methodology}

In this study, we analyzed a set of historical data on average monthly natural gas prices in three regions of the world: these data are provided free of charge by the World Bank for three regions - Europe, USA, Asia. Obviously, this set of prices is far from being exhaustive for a comprehensive analysis of the ongoing integration processes in the world. However, these three price parameters are sufficient for preliminary estimates with a high degree of accuracy, since these three points are indicators of regional prices.

The first hypothesis of the study is that the correlation between regional prices should increase as the global gas market develops. We believe that correlation analysis and comparative analysis are sufficient for formulating preliminary conclusions. More accurate estimates can be obtained using special econometric research methods, and they will probably be used in further research on this topic.

The second hypothesis assumes as the single global market develops, the share of spot contracts will increase in the structure of gas sales in all markets. If a global gas market is formed, long-term contracts are unlikely to be common. The study intends to conduct a comparative analysis of the available data provided by the International Gas Union.

The study also involves forecasting world gas prices. Such forecasts are always the result of an analysis of many factors, and in the framework of our brief study, such an approach would be redundant. Thus, we believe it is sufficient to look at the publicly available forecasts of specialized organizations. Using data from price forecasts, as well as analysis of research results from other scientists and opinions, we formulate our own forecast and assessment of the future development of the global gas markets. 


\section{Results: convergence of gas markets}

An example of an ideal global market for a product in today's world is the world oil market. Oil prices are very illustrative (see Fig. 1): Brent, WTI, Dubai, published by the World Bank. We pay attention to the highest degree of correlation of all prices with each other. Such a market can really be called a single market.

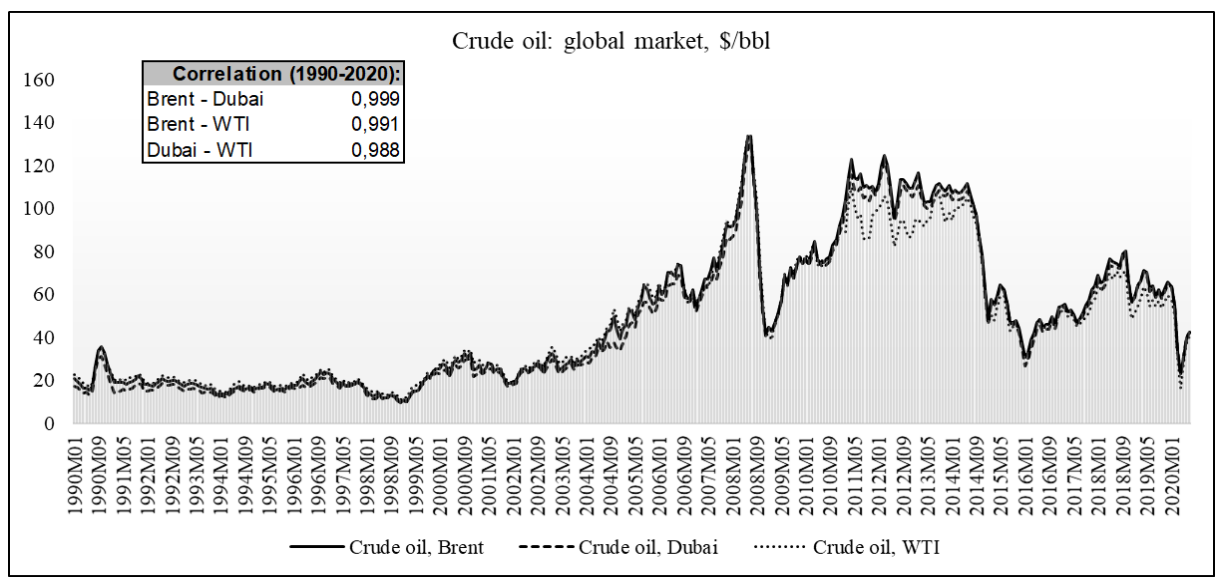

Fig. 1. Oil prices according to the World Bank

Source: [3]

Comparative and simple correlation analysis shows that natural gas prices do not depend on each other in such an obvious way (see Fig. 2). In the period 1990-2020, we see a correlation only between European and Japanese gas prices. But is this connection so obvious? Maybe there is a correlation at certain intervals? Maybe the correlation has increased in recent years? We tried to answer all these questions by dividing the considered period into several segments.

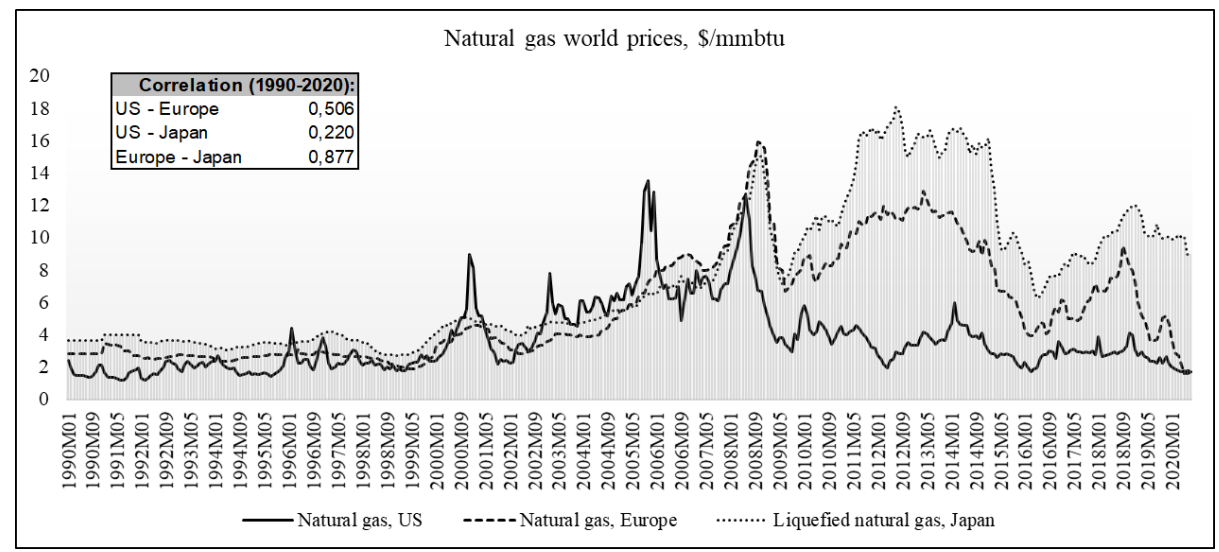

Fig. 2. Natural gas prices according to the World Bank

Source: [3]

The results of correlation analysis for different segments and price combinations of the three markets are presented in Table 1. The data show that there is no constant relationship between prices in different regions. Prices are correlated only in certain periods, which may be due to the temporary conditions of contracts, their connection with oil prices, or the 
orientation of the spot market towards general indicators. The values of the correlation coefficients 0.85 and higher are highlighted in gray.

Table 1. Correlation coefficients for gas prices

\begin{tabular}{|c|c|c|c|}
\hline & US - Europe & US - Japan & Europe - Japan \\
\hline $\mathbf{1 9 9 0 - 2 0 1 0}$ & 0,71 & 0,62 & 0,96 \\
\hline $\mathbf{2 0 0 0 - 2 0 2 0}$ & 0,26 & $-0,19$ & 0,79 \\
\hline $\mathbf{1 9 9 0 - 2 0 0 5}$ & 0,89 & 0,85 & 0,95 \\
\hline $\mathbf{2 0 0 5 - 2 0 2 0}$ & 0,35 & $-0,25$ & 0,66 \\
\hline $\mathbf{1 9 9 0 - 2 0 0 0}$ & 0,56 & 0,54 & 0,91 \\
\hline $\mathbf{2 0 0 0 - 2 0 1 0}$ & 0,47 & 0,30 & 0,93 \\
\hline $\mathbf{2 0 1 0 - 2 0 2 0}$ & 0,61 & 0,43 & 0,87 \\
\hline $\mathbf{1 9 9 0 - 1 9 9 5}$ & $-0,41$ & $-0,36$ & 0,78 \\
\hline $\mathbf{1 9 9 5 - 2 0 0 0}$ & 0,73 & 0,68 & 0,93 \\
\hline $\mathbf{2 0 0 0 - 2 0 0 5}$ & 0,85 & 0,87 & 0,96 \\
\hline $\mathbf{2 0 0 5 - 2 0 1 0}$ & 0,18 & $-0,11$ & 0,83 \\
\hline $\mathbf{2 0 1 0 - 2 0 1 5}$ & 0,17 & 0,02 & 0,02 \\
\hline $\mathbf{2 0 1 5 - 2 0 2 0}$ & 0,70 & 0,21 & 0,49 \\
\hline $\mathbf{1 9 9 0 - 1 9 9 3}$ & $-0,44$ & $-0,44$ & 0,74 \\
\hline $\mathbf{1 9 9 3 - 1 9 9 6}$ & 0,26 & 0,34 & 0,86 \\
\hline $\mathbf{1 9 9 6 - 1 9 9 9}$ & 0,38 & 0,38 & 0,83 \\
\hline $\mathbf{1 9 9 9 - 2 0 0 2}$ & 0,73 & 0,66 & 0,93 \\
\hline $\mathbf{2 0 0 2 - 2 0 0 5}$ & 0,89 & 0,89 & 0,98 \\
\hline $\mathbf{2 0 0 5 - 2 0 0 8}$ & 0,10 & 0,12 & 0,98 \\
\hline $\mathbf{2 0 0 8 - 2 0 1 1}$ & 0,58 & 0,08 & 0,63 \\
\hline $\mathbf{2 0 1 1 - 2 0 1 4}$ & $-0,32$ & $-0,31$ & 0,50 \\
\hline $\mathbf{2 0 1 4 - 2 0 1 7}$ & 0,84 & 0,78 & 0,95 \\
\hline $\mathbf{2 0 1 7 - 2 0 2 0}$ & 0,80 & 0,16 & 0,31 \\
\hline
\end{tabular}

Source: own calculations based on data from the World Bank [3]

We can often observe a correlation between the Asian and European markets. Why? Perhaps the answer lies in the nature of the pricing in these markets. The US gas market is likely to be independent.

Hypothesis 1 - the increase in correlation coefficients over time - has not been proven. Of course, the opposite has not been proven either, since the analysis is not enough deep. The use of more serious mathematical tools still allows us to highlight a slight tendency towards increased market correlation [4,5]. We will conduct a further step of research in the field of contracts under which the analyzed markets operate.

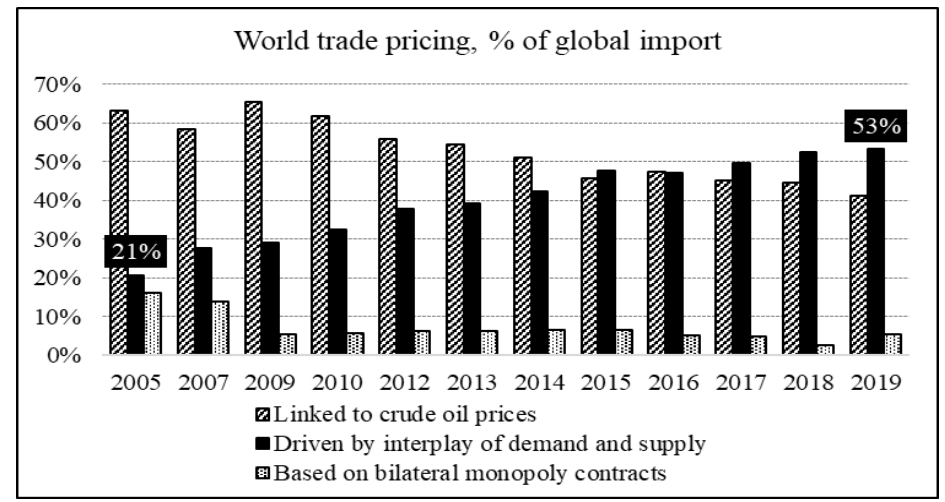

Fig. 3. Distribution of world trade by price formation mechanisms according to the IGU Source: [6] 
An alternative way to check the formation of a single gas market is to analyze the functioning of the market in terms of pricing mechanisms. Data for analysis is provided free of charge by the International Gas Union. According to these data, throughout the entire historical period (2005-2019), the average share of contracts issued on market principles is increasing (see Fig.3). If in 2005 the share of such contracts was 23\%, then by 2019 this share had increased to more than $50 \%$. What does this mean for gas globalization process? On average, worldwide, the share of sales in hubs, the share of spot deliveries, and other market instruments are increasing.

If we look at three markets: North America, Europe and Asia, we will see a difference in how prices are formed in these regions (we look at regional consumption parameters). The most unambiguous region is North America, which has a free market for natural gas. According to the IGU, more than $99 \%$ of prices in the market are formed on a market basis. Researchers note that previously, gas prices were correlated with oil prices in the US market, but gradually the factors of supply / demand / reserves for gas began to play a predominant role [7]. US gas prices are volatile due to seasonality effects and supply / demand shocks [8], the oil factor began to weaken after 2008 [9]. However, a deeper analysis using wavelet methods showed that the shale revolution and the weakening of the gap between gas prices and oil prices in the region still does not make gas prices independent of oil [10].

Europe is a market in which there is the possibility of supplying huge volumes of pipeline gas, which strives for non-market conditions. It means that the price may not be formed as a result of finding a balance between supply and demand at each short-term moment. The price may be the outcome of the agreement. One of these options is linking to oil prices. However, it has been shown that price convergence is limited not only within the world, but even within the European region. The formation of a single price space, in particular, is hindered by infrastructural restrictions in European countries [11].

The share of market contracts in 2005 in Europe was less than 15\%. In 2019, the share reached $78 \%$. European policy is aimed at the maximum transition of all contracts to exclusively market parameters (supply / demand balancing). The share of LNG is increasing, the share of spot supplies is increasing. This increase is likely to coincide with the fact that in recent years we have seen a correlation between European and American gas prices (see Table 1).

The Asia-Pacific market still mainly uses a pricing mechanism based on oil prices (over 60\%). The influence of oil indexing is also confirmed by empirical studies using VAR-models [12]. Such a price mechanism is assessed by researchers as more ineffective; it contributes to the formation of bubbles in the regional natural gas market [13]. There are bubbles in the markets of Asia, Europe and the United States, their causes are different: in Asia they are caused precisely by the orientation towards oil prices in conjunction with imbalances in supply / demand [14].

Hypothesis 2 - an increase in the share of spot contracts as markets converge - seems to be confirmed. But is there really a concern, that is the formation of a global gas market taking place? An interesting answer is offered by the IGU: this process is really going on and is confirmed by a gradual decrease in the coefficient of variation between prices in different markets. Certain features of the current global crisis can be harmful to the process of gas globalization, in particular, the payback of expensive infrastructure investments is very important for the development of the LNG market.

In the course of work on the study, we analyzed price forecasts from various agencies and organizations up to 2025. Predicting prices based on drivers is a more correct approach, but for this it will require a lot of research capabilities to form the predictions of the drivers themselves. For example, the forecast for US gas prices may depend on net crude oil imports [15] or shale gas production [16]. An interesting story is forecasting natural gas 
futures, where an adequate forecast is impossible without assumptions about jumps and their changes in time [17]. Moreover, spot prices depend on futures [18,19]. Decent performance can be shown, for example, by predictive methods based on machine learning methods [20].

The own study resulted in the average forecasts of natural gas prices (see Fig. 4) in the three main regions of the world above. In all price investigated forecasts, we can observe a similar dynamics of the development of the situation in the markets: first, a partial recovery in prices after the crisis fall in 2020; second, a long-term rise in prices due to rising costs and demand.

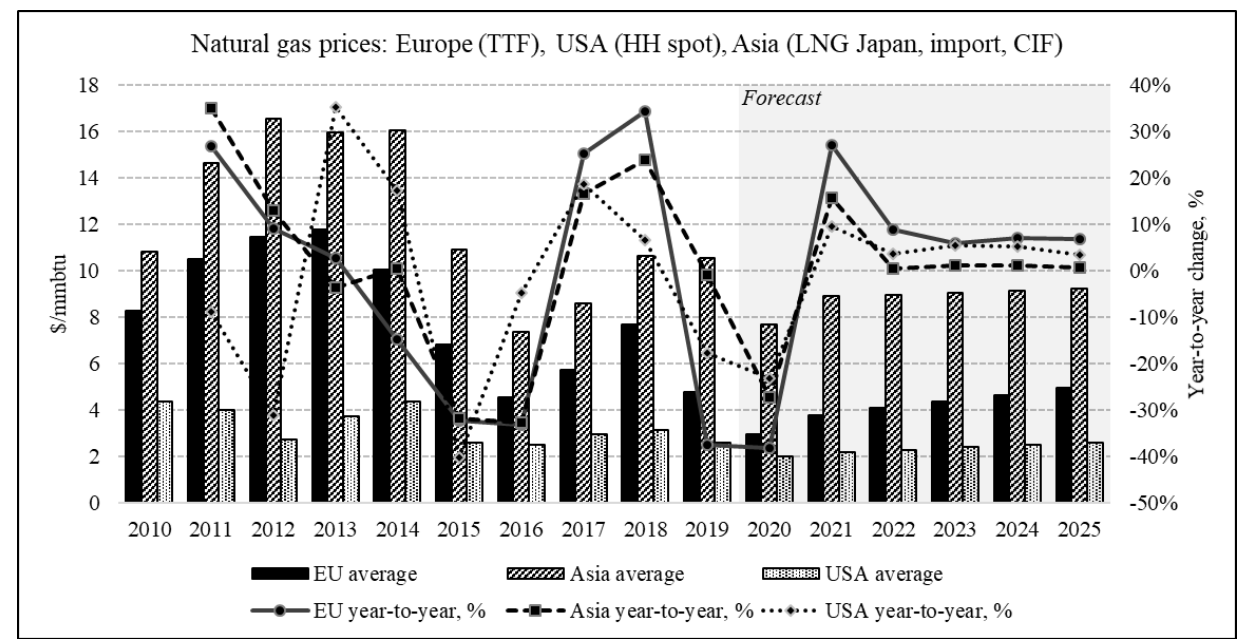

Fig. 4. Natural gas prices historical and predicted prices according to the authors' calculations based on data from World Bank, AEO, ERI RAS, IMF, WEO

Source: $[21,22,23,24]$

The analyzed price forecasts from different sources allowed us to conclude that the markets will indeed move synchronously in the same directions. The only difference can be in the pace of these changes. At the same time, although the correlation between annual gas prices in the United States and other regions will increase, it will not be sufficient to assert the formation of a global gas market by 2025 .

\section{Discussions}

Despite the fact that the empirical results obtained make it possible to provide answers to the hypotheses set, we recognize great opportunities for further analysis. Correlation analysis provides only preliminary estimates. Unfortunately, as mentioned above, there are different types of contracts in the gas markets. The markets of different regions and countries are very specific. These differences predetermine the limitations of correlation analysis. An analysis of the rules of the game in different markets is required - this is a qualitative analysis. Obviously, qualitative analysis does not allow us to digitize the degree of convergence of gas markets and to predict it reliably. In addition, analysis of convergence in gas markets can be carried out using a variety of statistical methods. Moreover, each of the statistical methods has its own limitations, features and a variety of interpretations of results. The results of some of these methods were used in the preparation of the article, links to the authors are given. In this case, particular importance should be given to the analyzed dataset and sample. The single global gas market is not only a coinciding time series of three prices (USA, Europe, Asia), but also: a whole range of 
quotes on exchanges, prices of long-term contracts, issues of state and international regulation, types of contracts and their number, and much more. In our article, we provide an analysis of convergence in terms of prices and contract types, which is only one part of this multifaceted topic.

\section{Conclusion}

The conducted research of historical gas prices has led to preliminary conclusions. Firstly, in the world there is a differentiation of regions in terms of natural gas markets, but there is no single market. This is proved by the low degree of dependence of prices in different markets among themselves, the absence of a stable strong correlation throughout the study period. Second, regional markets differ greatly in the types of pricing mechanisms used. Whereas the US uses an exclusive market-based competitive method, in Asia most gas contracts are made using the oil price indexation method. The active development of the gas market is taking place in Europe, it is potentially possible to move closer to the American one.

It can be argued that regional markets will continue to develop towards the formation of a global gas market. This is facilitated primarily by the development of the LNG market. However, the pace of development, as it was found out, will not bring obvious results in the next 5 years. The share of LNG trade is expected to increase, trade in hubs will expand, but regional specifics will still be strong.

\section{References}

1. Kumar, S., Kumar, A.P., Kumar, A.T., Kang, S.H. (2019). Correlations and volatility spillovers between oil, natural gas, and stock prices in India. Resources Policy, 62, 282-291.

2. Oglend, A., Osmundsen, P., Kleppe, T.S. (2020). Time Commitments in LNG Shipping and Natural Gas Price Convergence. The Energy Journal, 41(2), 29-46.

3. The World Bank. (2020, August 22). Commodity Markets. The World Bank. https://www.worldbank.org/en/research/commodity-markets

4. Chiappini, R., Jégourel, Y., Raymond, P. (2019). Towards aworldwide integrated market? Newevidence on the dynamics of U.S., European and Asian natural gas prices. Energy Economics, 81, 104740.

5. Kovacova, M., Kliestik, T., Valaskova, K., Durana, P., Juhaszova, Z. (2019). Systematic review of variables applied in bankruptcy prediction models of Visegrad group countries. Oeconomia Copernicana, 10(4), 743-772.

6. IGU Reports. (2020, August 12). Resources. IGU. https://igu.org/resources/

7. Wang, T., Zhang, D., Broadstock, D.C. (2019). Financialization, fundamentals, and the time-varying determinants of US natural gas prices. Energy Economics, 80, 707-719.

8. Hailemariam, A., Smyth, R. (2019). What drives volatility in natural gas prices? Energy Economics, 80, 731-742.

9. Ji, Q., Zhang, H.-Y., Geng, J.-B. (2018). What drives natural gas prices in the United States? - A directed acyclic graph approach. Energy Economics, 69, 79-88.

10. Kumar, A.T., Mukherjee, Z., Gupta, R., Balcilar, M. (2019). A wavelet analysis of the relationship between oil and natural gas prices. Resources Policy, 60, 118-124.

11. Bastianin, A., Galeotti, M., Polo, M. (2019). Convergence of European natural gas prices. Energy Economics, 81, 793-811. 
12. Zhang, D., Shi, M., Shi, X. (2018). Oil indexation, market fundamentals, and natural gas prices: An investigation of the Asian premium in natural gas trade. Energy Economics, 69, 33-41.

13. Zhang, D., Wang, T., Shi, X., Liu, J. (2018). Is hub-based pricing a better choice than oil indexation for natural gas? Evidence from a multiple bubble test. Energy Economics, 76, 495-503.

14. Li, Y., Chevallier, J., Wei, Y., Li, J. (2020). Identifying price bubbles in the US, European and Asian natural gas market: Evidence from a GSADF test approach. Energy Economics, 87, 104740.

15. Singh, D.R., Kumar, P. (2020). Statistical modelling of the natural gas prices in relation to demand, supply and economic growth indicators. Journal of Statistics and Management Systems, 23(4), 713-735.

16. Hu, H., Wei, W., Chang, C.-P. (2020). The relationship between shale gas production and natural gas prices: An environmental investigation using structural breaks. Science of the Total Environment, 713, 136545.

17. Li, B. (2019). Pricing dynamics of natural gas futures. Energy Economics, 78, 91-108.

18. Zhang, Y., Liu, L. (2018). The lead-lag relationships between spot and futures prices of natural gas. Physica A, 490, 203-211.

19. Meluzin, T., Zinecker, M., Balcerzak, A.P., Pietrzak, M.B. (2018). Why companies do not go public? Key factors to consider by IPO candidates in Poland and Czech Republic. Eastern European Economics, 56(6), 471-503.

20. Su, M., Zhang, Z., Zhu, Y., Zha, D., Wen, W. (2019). Data Driven Natural Gas Spot Price Prediction Models Using Machine Learning Methods. Energies, 12(9), 1680.

21. AEO 2020. (2020, January 29). Annual Energy Outlook 2020. U.S. Energy Information Administration. https://www.eia.gov/outlooks/aeo/

22. ERI RAS. (2019). Global and Russian Energy Outlook 2019. The Energy Research Institute of the Russian Academy of Sciences. https://www.eriras.ru/data/45/eng

23. IMF. (2020, August 22). IMF Primary Commodity Prices. International Monetary Fund. https://www.imf.org/en/Research/commodity-prices

24. WEO 2019. (2019, November). World Energy Outlook 2019. IEA. https://www.iea.org/reports/world-energy-outlook-2019 